\title{
The hidden injury. Updating awareness of the latest research of concussion in tennis
}

\author{
Janet A. Young ${ }^{a} \&$ Alan J. Pearce ${ }^{b}$ \\ ${ }^{a}$ Victoria University, Melbourne Australia. ${ }^{\mathrm{b}}$ La Trobe University, Melbourne Australia.
}

\section{ABSTRACT}

This article updates coaches and tennis sports scientists on recent changes to the consensus statement for sports-related concussion. Specifically, the article provides new information that can be applied to tennis. While concussion in tennis is rare, head injuries in tennis do occur. It is important that in-lieu of medical staff available at training or tournaments, coaches and sports science practitioners are concussion aware.

\author{
Key words: concussion, injury, \\ tennis, head injury. \\ Received: 29 May 2019 \\ Accepted: 02 July 2019 \\ Corresponding author: Janet $A$. \\ Young, First Year College, \\ Victoria University, Melbourne, \\ Australia. Email: \\ janet.young@vu.edu.au
}

\section{INTRODUCTION}

The issue of sports concussion continues to permeate throughout all sports. While of greatest concern in contact sports such as the football codes, this does not mean that athletes are immune to concussion injuries in non-contact sports such as tennis. Previous injury studies have reported that concussions in tennis are rare (Pluim, Staal, Windler, \& Jayanthi, 2006). However, our previous article (Pearce \& Young, 2016) highlighted a number of tennis case studies (e.g. Casey Dellaqua, Eugenie Bouchard, and Victoria Azarenka). Therefore, the issue is still of concern to tennis coaches and sports science staff working with players of all ages and abilities.

The Consensus Statement on Concussion in Sport has recently been updated (McCrory et al., 2017). This statement has revised guidelines that are important for all coaches. The aim of this article is to present some of the new information contained in the Consensus Statement that tennis coaches and support staff can review and apply to their players. These include the evolving nature of the injury, courtside assessment protocols, and recovery. For basic information regarding concussion recognition and prevention of concussion during tennis training, the reader is referred to Pearce and Young (2016).

\section{Concussion is an invisible and evolving injury}

Most concussion symptoms appear quickly but also spontaneously resolve (McCrory et al., 2017). However, concussion is an evolving injury whereby symptoms may not appear immediately, but sometimes after a few hours and over the course of several days (Elkington, Manzanero, \& Hughes, 2019; McCrory et al., 2017). Research is still aiming to understand why this happens. Latest evidence suggests that concussion affects the brain's physiology and if surpassing a threshold observable signs and symptoms will occur. This means that as the brain's physiological environment is dynamic and changes can occur over time (Giza \& Hovda, 2001), it is important that once an athlete is suspected of concussion that he/she is monitored in case delayed symptoms appear. Even if symptoms disappear, coaches and support staff must remain vigilant, particularly if an athlete who has recently sustained a concussion reports he/she is not feeling well, or starts to look unwell, when increasing his/her exercise intensity. As reported by Victoria Azarenka,

"I was warming up in the gym...when I fell while running a sprint...I fell forward and hit my arm and head. I was checked by the medical team before I went on the court and they were courtside for monitoring. I felt worse as the match went on, having a headache and feeling dizzy. I also started having trouble seeing and felt weak before I fell. I was taken to the hospital for some medical tests and have been diagnosed with a concussion" (Newman, 2010). 
Protocols and process in applying the concussion protocol with suspected concussion

The latest Consensus (McCrory et al., 2017) protocols for evaluation of athletes with a suspected concussion have not, in principle, changed from the previous statement (McCrory et al., 2013). Firstly, it is important to note that players suspected of concussion should be removed from courtside for an assessment. Secondly, while signs and symptoms may appear obvious, only a licenced medical practitioner is able to formally diagnose a concussion. The reason for this is that there are overlapping signs and symptoms between concussion and other conditions such as heat stress/stroke, whiplash and facial injuries.

However, for the majority of sports participation (including tennis), a medical doctor is not present. Indeed, any health practitioner being present at training or a non-professional tournament is the exception rather than the rule. So what can be done in this situation? The consensus statement does provide the opportunity for non-medically trained personnel to recognise the signs of concussion for which there are two well-known instruments. The Concussion Recognition Tool (version 5) is a pocket-sized card that lists the 'red-flags' of concussion that require an ambulance; then if no 'red-flags' are apparent, simple steps to observe signs and symptoms in the individual (Echemendia et al., 2017). A second assessment that is gaining popularity is the King-Devick (KD) test. A simple number reading tool that can be used on any tablet device, the KD has demonstrated good reliability and validity in recognising concussion (Galetta et al., 2016; Nguyen, King, $\&$ Pearce, in press; Rist, Cohen, \& Pearce, 2017).

\section{Return to play, rest is no longer best}

The most significant change in post-concussion management in recent years is that complete rest is no longer the standard treatment after a concussion (McCrory et al., 2017). Emerging evidence suggests that after a brief period of rest, light aerobic activity where the level of the activity does not bring on or worsen symptoms is now encouraged. However, it is still agreed that vigorous exertion while an athlete is recovering is not permitted. This is because vigorous exercise intolerance may be due to autonomic nervous system dysfunction (Leddy, Haider, Ellis, \& Willer, 2018). More recently research (Pearce, Tommerdahl, \& King, in press) has shown central nervous system changes that may also contribute to exercise intolerance and general fatigue.

While it is difficult to present generic exercise guidelines, it is accepted that the Buffalo Graded test is a reliable and valid systematic evaluation of exercise intolerance post concussion (Leddy \& Willer, 2013). Specifically, the test involves quantifying heart rate responses, allowing for the prescription of individualised exercise intensities below the heart rate that can bring on an individual's symptoms (Leddy et al., 2018). These authors suggest that having known heart rate concussion thresholds allows for precision dosage of exercise prescription thereby improving the efficacy of the recovery phase and potentially reducing the risk of persistent postconcussion symptoms (Leddy et al., 2018).

Recovery is not a linear path

Knowing when an athlete is ready to return to play is an immense area of interest, and knowing when to return to competition for tennis players is also very important. An update from the latest Consensus highlights the definition of recovery being a resolution of post-concussion symptoms and the individual showing normal motor (i.e. balance) and cognitive functioning (McCrory et al., 2017).

While it is generally accepted that a large majority of concussed athletes recover from clinical symptoms within four weeks, it is also appreciated that neurophysiological and psychological recovery can extend beyond the clinical timeline in some individuals. Moreover, recovery does not occur in a uniform manner; indeed, there is a heterogeneous recovery timeline for athletes. As reported by Casey Dellacqua,

At the time [of the concussion] I thought a couple of weeks, I'll be fine, I'll be sweet, because I had the championships coming up. But as the weeks went on, my symptoms got worse and worse. I was in a fog for two weeks. I had headaches, I couldn't go on my phone or watch TV, I was so sensitive to light. And I was just sleeping for ages. And then I went to having almost insomnia where I couldn't sleep...So it was a combination of things. It was pretty scary at the time, because obviously with brain injuries l'd never experienced that and it's a very bizarre tennis injury (Trollope, 2016).

\section{Juniors take longer than senior players for recovery}

Concussion research in children (under 12 years) and adolescents (13-18 years) is limited, relative to research on concussion in adults. Therefore the latest guidelines have not been able to articulate specific protocols for concussion recovery management between children, adolescents and adults (McCrory et al., 2017). However, it is generally agreed that due to the developing brain, children and adolescents should take longer before returning to high intensity training and competition, compared to adults. Recently, it has been suggested that a child's return to sport program, including tennis, should be extended so that the child does not return to intense exercise less than 14 days from the resolution of all symptoms (Elkington et al., 2019)

Most importantly, children and adolescents should not return to training and competition, until they have successfully returned to school without exacerbation of symptoms (McCrory et al., 2017). During this time, however, it is appropriate that they undertake symptom-free exercise rehabilitation (Leddy, Baker, \& Willer, 2016). 


\section{CONCLUSION - IMPLICATIONS FOR COACHES}

Although the known dangers of head trauma in sport dates back over 90 years (Martland, 1928), the increasing interest in sports concussion is furthering our understanding of the injury, including tennis.

While concussion is rare in tennis (Pluim et al., 2006) it is important that coaches and sports scientists are not complacent about the issue. Recent case study examples have shown that tennis players can be affected for many months after a concussion injury (Pearce \& Young, 2016).

The aim of this paper was to update new information gathered through scientific research, as well as translating the latest outcomes from the 2017 Consensus Statement that are applicable to tennis coaches. Although concussion science will continue to develop, it is important that coaches understand that no two athletes will react the same way following a concussion. Moreover, no two players will have a uniform recovery timeline. Low-intensity exercise that does not aggravate or worsen symptoms is now encouraged, compared to complete rest. Further, more conservative rehabilitation regime is required for children and adolescent players who have been concussed.

In all cases, if there is ever any uncertainty of a player being concussed or fully recovered, after being concussed, remember the mantra: if in doubt sit them out.

\section{REFERENCES}

Echemendia, R. J., Meeuwisse, W., McCrory, P., Davis, G. A., Putukian, M., Leddy, J., Makdissi, M., Sullivan, S. J., Broglio, S. P., \& Raftery, M. (2017). The concussion recognition tool 5th edition (CRT5): background and rationale. British Journal of Sports Medicine, 51(11), 870-871, https://doi.org/10.1136/bjsports-2017-097508

Elkington, L., Manzanero, S., \& Hughes, D. (2019). Concussion in Sport Position Statement. Canberra: Sport Australia

Galetta, K. M., Liu, M., Leong, D. F., Ventura, R. E., Galetta, S. L., \& Balcer, L. J. (2016). The King-Devick test of rapid number naming for concussion detection: meta-analysis and systematic review of the literature. Concussion, 1(2), CNC8, https://doi.org/10.2217/cnc.15.8

Giza, C. C., \& Hovda, D. A. (2001). The neurometabolic cascade of concussion. Journal of Athletic Training, 36(3), 228-235.

Leddy, J. J., Baker, J. G., \& Willer, B. (2016). Active Rehabilitation of Concussion and Post-concussion Syndrome. Physical Medicine and Rehabilitation Clinics of North America, 27(2), 437-454, https://doi.org/10.1016/j.pmr.2015.12.003

Leddy, J. J., Haider, M. N., Ellis, M., \& Willer, B. S. (2018). Exercise is medicine for concussion. Current Sports Medicine Reports, 17(8), 262 270, https://doi.org/10.1249/JSR.0000000000000505

Leddy, J. J., \& Willer, B. (2013). Use of graded exercise testing in concussion and return-to-activity management. Current Sports Medicine Reports, 12(6), 370-376, https://doi.org/10.1249/JSR.0000000000000008

Martland, H. S. (1928). Punch drunk. Journal of the American Medical Association, 91(15), 1103-1107, https://doi.org/10.1001/jama.1928.02700150029009

McCrory, P., Meeuwisse, W., Dvorak, J., Aubry, M., Bailes, J., Broglio, S., Cantu, R. C., Cassidy, D., Echemendia, R. J., Castellani, R. J., Davis, G. A., Ellenbogen, R., Emery, C., Engebretsen, L., Feddermann-Demont, N., Giza, C. C., Guskiewicz, K. M., Herring, S., Iverson, G. L., Johnston, K.
M., Kissick, J., Kutcher, J., Leddy, J. J., Maddocks, D., Makdissi, M. Manley, G., McCrea, M., Meehan, W. P., Nagahiro, S., Patricios, J., Putukian, M., Schneider, K. J., Sills, A., Tator, C. H., Turner, M., \& Vos, P. E. (2017). Consensus statement on concussion in sport-the 5 th international conference on concussion in sport held in Berlin, October 2016. British Journal of Sports Medicine, 51, 838-847, https://doi.org/10.1136/bjsports-2017-098065

McCrory, P., Meeuwisse, W. H., Aubry, M., Cantu, B., Dvořák, J., Echemendia, R. J., Engebretsen, L., Johnston, K., Kutcher, J. S., Raftery, M., Sills, A., Benson, B. W., Davis, G. A., Ellenbogen, R. G., Guskiewicz, K., Herring, S. A., Iverson, G. L., Jordan, B. D., Kissick, J., McCrea, M., McIntosh, A. S., Maddocks, D., Makdissi, M., Purcell, L., Putukian, M., Schneider, K., Tator, C. H., \& Turner, M. (2013). Consensus statement on concussion in sport: the 4th International Conference on Concussion in Sport held in Zurich, November 2012. British Journal of Sports Medicine, 47(5), 250-258, https://doi.org/10.1136/bjsports2013-092313

Newman, P. (2010). Azarenka's collapse caused by 'mild concussion' not searing heat. Independent. Retrieved from https://www.independent.co.uk/sport/tennis/azarenkas-collapsecaused-by-mild-concussion-not-searing-heat-2067937.html

Nguyen, M., King, D., \& Pearce, A. (in press). A reliability and comparative analysis of the new randomized King-Devick test. Journal of NeuroOpthamology.

Pearce, A. J., Tommerdahl, M., \& King, D. A. (in press). Neurophysiological Abnormalities in Individuals with Persistent Post-Concussion Symptoms. Neuroscience.

Pearce, A. J., \& Young, J. A. (2016). Hard knocks: Concussion injuries in tennis. ITF Coaching and Sport Science Review, 70, 5-7.

Pluim, B. M., Staal, J., Windler, G., \& Jayanthi, N. (2006). Tennis injuries: occurrence, aetiology, and prevention. British Journal of Sports Medicine, 40(5), 415-423, https://doi.org/10.1136/bjsm.2005.023184

Rist, B., Cohen, A., \& Pearce, A. J. (2017). King-Devick performance following moderate and high exercise intensity bouts. International Journal of Exercise Science , 10(4), 619-628.

Trollope (2016). Checking in with...Casey Dellaqua. Retrieved from http://www.tennis.com.au/news/2016/09/22/checking-in-with-caseydellacqua

\section{RECOMMENDED ITF TENNIS ACADEMY CONTENT (CLICK BELOW)}

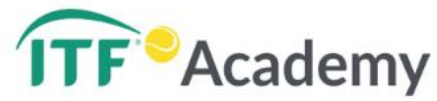

Copyright (c) 2019 Janet A. Young \& Alan J. Pearce

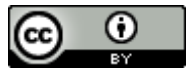

This text is under a Creative Commons BY 4.0 license

You are free to Share - copy and redistribute the material in any medium or format - and Adapt the content - remix, transform, and build upon the material for any purpose, even commercially under the following terms:

Attribution: You must give appropriate credit, provide a link to the license, and indicate if changes were made. You may do so in any reasonable manner, but not in any way that suggests the licensor endorses you or your use.

CCBY4.0 license terms summary CCBY4.0license terms 